\begin{tabular}{|c|c|}
\hline & Asian Social Work Journal (ASWJ) \\
\hline $\begin{array}{c}\text { ASIAN SOCIAL WORK } \\
\text { JOURAL } \\
\text { (ASW) }\end{array}$ & Volume 4, Issue 3, July 2019 \\
& e-ISSN : 0128-1577 \\
& Journal home page: \\
& www.msocialwork.com \\
\hline
\end{tabular}

\title{
Demands and Factors Associated to Psychosocial Support of Cancer Patients at Vietnam National Cancer Hospital
}

\author{
Pham Tien Nam ${ }^{1}$, Le Tu Hoang2 ${ }^{2}$ Nguyen Kim Oanh ${ }^{1}$, Nguyen Khac Liem ${ }^{3}$, Hoang Van Minh ${ }^{4}$ \\ 1Department of Social Work, Faculty of Social Science, Behavior, and Health Education, Hanoi University of Public \\ Health, Vietnam \\ ${ }^{2}$ Health Biostatistics, Hanoi University of Public Health, Vietnam \\ ${ }^{3}$ Clinic Medicine Department, Hanoi University of Public Health, Vietnam \\ 4Hanoi University of Public Health, Vietnam \\ Correspondence: Pham Tien Nam (ptn1@huph.edu.vn)
}

\begin{abstract}
Cancer patients in Vietnam are increasing exponentially in numbers, with great demands for psychosocial support. This study explored the demands for the psychosocial support of cancer patients at Vietnam National Cancer Hospital and several associated factors. This is a cross-sectional survey, qualitative and quantitative study, and conducted from April to September 2017. This study utilized the structured questionnaire of 418 cancer patients, 8 in-depth interviews and 3 focus group discussions. Results of the study showed that cancer patients have different demands for 6 types of psychosocial support services, specifically: visiting about health and family difficulties (86.1\%), providing information on supporting networks for cancer patients $(75.7 \%)$, psychological counseling and consultation $(68.4 \%)$, psychotherapy $(49.9 \%)$, Consultation on self-care for appearance $(39.1 \%)$, and Consultation on social communication (38.6\%). Factors associated to cancer patients' demands for psychosocial support at Vietnam National Cancer Hospital are gender, the number of treatments, and psychological states. In addition, to improve the quality of life for cancer patients, Vietnam National Cancer Hospital should promote psychosocial support activities for cancer patients, based on associated factors.
\end{abstract}

Key words: demands, psychosocial support, cancer patients, Vietnam National Cancer Hospital

\section{Introduction}

Cancer is the second leading cause of death globally. In 2012, there were 8.2 million deaths from in the world. Annual deaths will increase from 14.1 million in 2012 to 21.6 million in 2030. About $75 \%$ of cancer deaths occur in low- and middle-income countries, where the number of cancer cases is increasing most rapidly (World Health Organization (WHO), 2017). As in other countries in the world, Vietnam's number of cancer patients is also rising, among all social levels, ages and professions. According to records about cancer situation in Hanoi, Ho Chi Minh City and some provinces, it is estimated that there are 150,000 new cancer cases annually and 75,000 deaths from cancer in the country. These numbers have tendency to raise. By 2020, there will be about 200,000 new cases and 100,000 deaths from cancer (Ministry of Health, 2015).

Although there have been some medical advances made in the fields of early diagnosis and treatment to help cancer patients extend their life, the survivors of cancer often still face a number of difficulties. In addition to the physical pain and unwanted effects caused by treatments, many cancer patients also 
suffer from psychological problems such as depression, anxiety, inferiority, low self-esteem, stress, prone to excitement/ irritation, etc. Some cancer patients face crisis, with higher risk of committing suicide. In addition to the above problems, cancer patients also face some social problems, namely the problem of social relationships between patients with family members, patients with medical staff and medical facilities. Along with radical cancer treatment methods, mental health and social care are essential, contributing to improving their quality of life and treatment. To better care for cancer patients, it is important to understand the psychological states of cancer patients and their demands for psychosocial support. However, research on this issue in Vietnam remains very limited. Therefore, this study aims to assess demands and factors associated to psychosocial support of cancer patients at Vietnam National Cancer Hospital.

\section{Methods}

\section{Study setting}

The study was conducted at the Vietnam National Cancer Hospital, a Vietnamese hospital specialized in tumor treatment under the Ministry of Health. Each year the hospital has over 360,000 visitors and over 36,000 patients staying for treatment. The hospital has 3 treatment facilities, with 31 functional rooms, 1500 beds. This study was conducted at the head office, at Tan Trieu Commune, Thanh Tri District, Hanoi, where most of the departments and beds are located, and at the Center for Palliative Care \& Pain Prevention in Tuu Liet village, Tam Hiep commune, Thanh Tri district, Hanoi.

\section{Study design and sample size}

The study combined quantitative and qualitative research methods. Quantitative research was used to clarify cancer patients' demands and associated factors such as demographic and treatment characteristics (gender, the number of treatments and psychological states). This study was using the formula of a population proportion to calculate the sample size:

$$
n=\frac{z_{1-\alpha / 2} \times p \times(1-p)}{d^{2}}
$$

In which: confidence level $(\alpha)$ was $95 \%$, absolute precision required (d) was 0.05 , population proportion (p) was 0.5 as it wasn't any similar study on this topic. The calculated sample size (after adding $10 \%$ of withdrawal) was 418 cancer patients including 338 of them staying at the Head office and 80 at the Center for Palliative Care and Pain Prevention. In this study, the number of cancer patients was selected according to the department, with the main treatment method. At the survey, the number of cancer patients with three treatment methods (surgery, radiotherapy, chemotherapy) studied in Tan Trieu were 338 cancer patients. The number of cancer patients with palliative care was too little in Tan Trieu, so the method of palliative care was further investigated in Tam Hiep with 80 cancer patients. Criteria for selection include: (1) Patients who have been diagnosed with cancer, receiving treatment at the Vietnam National Cancer Hospital, not belonging to benign tumor group, or have precancerous tumors such as malformations, inflammation; (2) Patients aged over 18, who are physically fit enough to partake in interview; (3) Patients without disabilities such as deafness, blindness, muteness, etc. or neurological disorders such as epilepsy, disability, etc.; have legal responsibilities, are selected according to the department of treatment, classified by 4 treatment methods: surgery, chemotherapy, radiation therapy and palliative care. In fact, depending on the severity level, patients use a combination of 1-2 treatments. Sample size is gender equivalent.

Qualitative research was used to collect more in-depth information from cancer patients, family members, medical staff and social workers on the demands for psychosocial support of cancer patients at Vietnam National Cancer Hospital. The study conducted 8 in-depth interviews including 1 Head of Social work office, 1 Social worker, 1 Head of Treatment department, 1 Head of Nursing department, 3 cancer patients, 1 caregiver, and 3 focus group discussions including 1 focus group discussion with 5 female cancer patients, 1 focus group discussion with 10 male cancer patients, and 1 focus group 
discussion with 7 social workers. When taking part in in-depth interviews and focus group discussion, all participants must know how to read and write. Besides, they must have a good health and agree to participate in the discussions. Cancer patients must meet criteria for selection as mentioned in the quantitative research.

\section{Study variables}

For quantitative research, the study's variables included independent variable and dependent variable groups. Independent variable included 3 groups (demographic characteristics, treatment characteristics, and psychological states). Variables on demographic and treatment characteristics included gender, age group, type of disease, treatment methods, and the number of treatments. Variable on psychological characteristics included 5 psychological states of cancer patients based on the 5 stages of grief of the Kubler-Ross model (1969): Denial (Shock; disbelief in the results of the diagnosis); Anger (Stress, anxiety, excitability); Bargaining (Trust in the treatment process; Hope/ desire to be cured); Depression (Silence, crying, and grief) and Acceptance (Accept to live with the disease and ready to face the worst possible situation). 418 cancer patients were questioned at each stage of psychosocial state by Yes or No since being diagnosed, in the past month.

Dependent variable was demands for psychosocial support, including 6 single variables (demand for receiving visits about health and family difficulties; psychological counselling and consultation; psychological therapy; consultation on the self-care of appearance; consultation on social communication and providing information of supporting network for cancer patients). This dependent variable was measured on a Likert scale, consisting of 5 levels (absolutely unnecessary, unnecessary, normal, necessary, and very necessary).

For qualitative research, study content was focused on analyzing 6 demands of psychosocial support of dependent variable as mentioned above.

\section{Data processing and analysis}

The study's quantitative data were analyzed using Stata version 14.0. Descriptive statistics was used to describe the characteristics of participants. Univariate analysis was applied to see the relationship between outcome variables with each of independent variables with significant level $\alpha=0.05$, the strength of relationships was estimated using OR and $95 \%$ CI. We also used multivariate analysis with logistics regression model based on one out of 2 conditions for variables selection: if p-value in univariate analysis below $0.05 \mathrm{OR}$ in the range from 0.05 to 0.1 . Final models were decided if one variable have $\mathrm{p}$-value $<0.05$ when adjusted to other variables, and their real meanings when having these variables in model.

Dependent variable on the demands of psychosocial support was regrouped into 2 categories: Yes (normal, necessary, and very necessary) and No (absolutely unnecessary, and unnecessary).

Qualitative data from in-depth interviews and focus group discussions were processed on NVivo 7.0 software. This is a computer program that organizes repeating themes and aids in the coding of transcripts. Each transcript will be reviewed independently by 2 researchers. Derived from a review of the literature and study's questionnaire, themes emerging from the interviews and focus group discussions will be used to create categories and subcategories for the coding framework. To make more deep information, each demand of psychosocial support will be presented by the in-depth interview or focus group discussion.

\section{Ethical approval of the study}

The study was approved through the Institutional Review Board of Hanoi University of Public Health. Process of data collection and use for analysis were also approved by the Director of Vietnam National Cancer Hospital. While surveying, if research's voluntary participants feel uncomfortable with any question, they have the right to refuse to answer. 


\section{Results}

\section{Demographic characteristics, treatment characteristics and psychological states of cancer patients}

As showed in table 1, there are $48.6 \%$ male and $51.4 \%$ female out of the 418 cancer patients surveyed. Patients in working age under 55 years old account for $48.1 \%$ and $51.9 \%$ for that of group aged over 55. Patients have various types of cancer, of which the most common are gastrointestinal cancer (38.9\%), ovarian cancer (17\%), breast cancer (11.8\%), lung cancer $(9.4 \%)$; and other cancers such as skin, pancreas, adrenal gland, liver cancer, and etc., account for $19.9 \%$. Patients having first-time treatment at the hospital account for $57.7 \%$ Depending on pathological degree, patients are assigned for the combined treatment methods, of which the percentage of patients receiving chemotherapy, radiotherapy, surgery and palliative care are $30.5 \%, 27.5 \%, 22 \%$ and $20 \%$ respectively.

Table 1. Demographic characteristics, treatment characteristics and psychological states of cancer patients at Vietnam National Cancer Hospital

\begin{tabular}{|c|c|c|c|}
\hline \multicolumn{2}{|c|}{$\begin{array}{c}\text { Demographic characteristics, treatment characteristics and } \\
\text { psychological states }\end{array}$} & $\mathbf{N}$ & $\%$ \\
\hline \multicolumn{2}{|l|}{ Total number of patients } & 418 & 100.0 \\
\hline \multirow{3}{*}{ Gender } & Male & 203 & 48.6 \\
\hline & Female & 215 & 51.4 \\
\hline & $18-26$ & 12 & 2.9 \\
\hline \multirow{3}{*}{ Age group } & $27-40$ & 44 & 10.5 \\
\hline & $41-55$ & 145 & 34.7 \\
\hline & Above 56 & 217 & 51.9 \\
\hline \multirow{6}{*}{ 3. Types of cancer } & Breast cancer & 49 & 11.8 \\
\hline & Lung cancer & 39 & 9.4 \\
\hline & Uterus and ovarian cancer & 71 & 17.0 \\
\hline & Gastrointestinal cancer & 162 & 38.9 \\
\hline & Thyroid cancer & 13 & 3.1 \\
\hline & Others & 83 & 19.9 \\
\hline \multirow{4}{*}{ 4. Treatments methods } & Surgery & 88 & 22.0 \\
\hline & Chemotherapy & 122 & 30.5 \\
\hline & Radiotherapy & 110 & 27.5 \\
\hline & Palliative care & 80 & 20.0 \\
\hline \multirow{2}{*}{ 5. Number of treatments } & First time & 241 & 57.7 \\
\hline & 2 times and more & 159 & 42.3 \\
\hline \multicolumn{4}{|c|}{ 6. Psychological states (based on the Kubler-Ross model - 1969) } \\
\hline \multicolumn{2}{|c|}{ 6.1. Denial (Shock; disbelief in the results of diagnosis) } & 212 & 50.8 \\
\hline \multicolumn{2}{|c|}{ 6.2. Anger (Stress, anxiety, and excitability) } & 258 & 61.9 \\
\hline \multicolumn{2}{|c|}{ 6.3. Bargaining (Trust in the treatment process, hope/desire to be cured) } & 408 & 98.3 \\
\hline \multicolumn{2}{|c|}{ 6.4. Depression (Silence, Crying, and grief) } & 174 & 42.1 \\
\hline \multicolumn{2}{|c|}{$\begin{array}{l}\text { 6.5. Acceptance (Accept to live with the disease and ready to face the } \\
\text { worst possible situation) }\end{array}$} & 317 & 76.4 \\
\hline
\end{tabular}

According to the Kubler-Ross model of patients' 5 stages of grief (1969), the data showed that, since being diagnosed, in the past month, stage 3 accounts for a highest percentage, with $98.3 \%$ of patients having Bargaining state (Trust in treatment process, hope/desire to be cured). When it is time to face the disease at stage $5,76.4 \%$ of patients accept their condition, are willing to live with the disease and ready to face the worst possible situation. Patients with negative psychological states have a lower percentage than patients with positive psychological states, namely: at stage $2,61.9 \%$ of patients are 
angry and frustrated when facing their illness; at stage 1, more than half $(50.8 \%)$ of the patients feel shocked and want to deny the truth about their disease; and $42.1 \%$ of patients have depression (silence, crying, and grief) at stage 4.

\section{Demands for the psychosocial support of cancer patients}

Psychosocial support for cancer patients involves supportive activities for cancer patients to relieve their psychological stress, depression, and increase social interaction. As a result, cancer patients can receive treatment regimens and overcome their disease.

Chart 1. Demands for the psychosocial support of cancer patients at Vietnam National Cancer Hospital

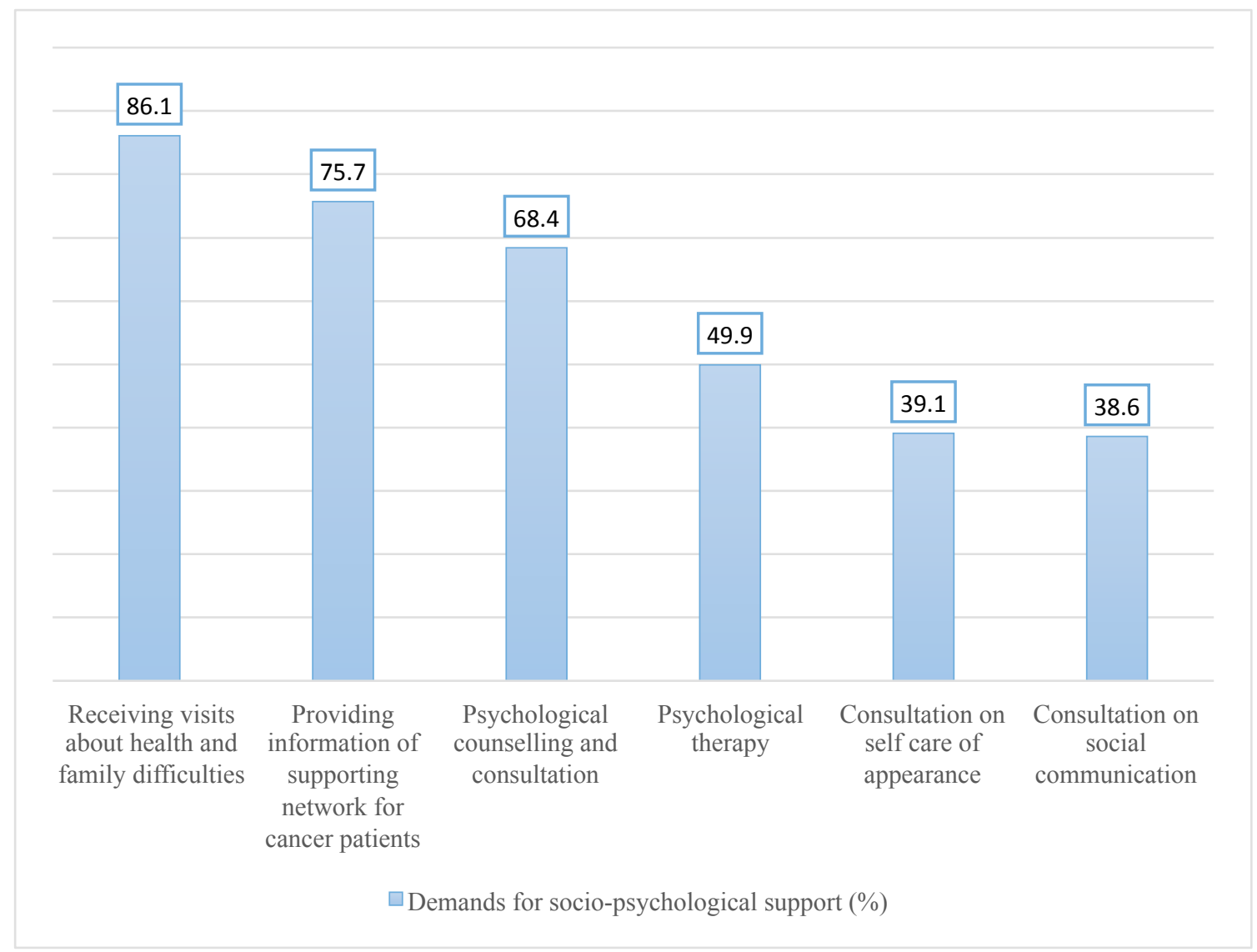

Chart 1 showed that cancer patients' demands for psychosocial support include: Receiving visits about health and family difficulties (86.1\%); Providing information of supporting network for cancer patients (75.7\%); Psychological counselling and consultation to relieve their negative psychological states (68.4\%); then followed by demands for psychotherapy with nearly $50 \%$; Consultation on the self-care of appearance (39.1\%); Consultation on social communication $(38.6 \%)$.

"In general, the patients' psychological states vary, so their demands for psychological support is relatively large and should be followed throughout the course of treatment of patients" (In-depth interview - Head of Social Work Office).

When being admitted to treatment, firstly the patients want to receive visits from social workers or medical staff, counselling on their health conditions and family difficulties, explaining to them about related issues during the treatment at the hospital, and encouraging them to follow the treatment regimen.

"At the beginning of treatment period, we have many concerns, the first concern is the lack of financial resource for treatment, the second is our fear of not being able 
to cure our illness; sometimes we haven't thought clear about this and become very depressed, we could only cry when thinking about our illness, do not know if it can be cured. Therefore, we really need the staff's visit and encouragement during this time..." (Focus group discussion - female patient, Surgical Department 2).

In the course of treatment, cancer patients need psychological counseling to obtain information about the cause, signs, symptoms, prevention and treatment of mental disorders that they are having. Psychological counseling is also essential for cancer patients to help them participate and share their worries, thereby relieving their anger and frustration.

"Cancer patients like us need a psychologist for counseling; then we would know how much time we have, and what treatment we need to have so that we will feel more secure when living with our illness" (In-depth interview - female patient, Surgical Department 2).

For patients with severe psychological problems such as high-level depression or psychological crisis, they require psychotherapy to minimize the risk of self or harm to other individuals.

"Patients at this hospital need support and psychological treatment. In the past, there were three patients committing suicide when they found out they had cancer". (In-depth interview - Head of Nursing Department).

Connecting and providing information about supporting network for cancer patients is an activity to assist the cancer patients with the opportunity to participate in the network, provide additional psychosocial counselling, and better understand about their conditions, how to live with the disease, build their confidence in relationships with others, and etc. In the opinion of medical staff, the cancer patients are in need of information about the supporting network. This is to help them gain more access to the pathological details and to share their experience with people with the same condition.

\footnotetext{
"From my personal point of view, cancer patients have a high demand for access to social service resources through cancer patient supporting networks. In addition to physical support, psychological support is also necessary for their effective treatment" (Focus group discussion - Social workers).
}

Consultation on the self-care of appearance is an activity that helps cancer patients understand themselves, their behaviors, their beliefs and motivations, and especially to help them understand that love and care for themselves are essential. Meanwhile, social communication consultation is a supportive activity for cancer patients to encourage them to overcome the inferiority, low self-esteem, and etc. in communication. As a result, they will be more active in exchanging information and interacting with others such as other patients, family members, and medical staff. The results show that demands for self-care and social consultation is particularly concerned by the female patients:
"About 2-3 months ago, I watched a show on VTV1, reported at a Japanese hospital, on their highest floor, they have a very large area, all the patients from young to old are encouraged to go there. There is a very long table, 10 to 15 meters long, where nursing staff encourage the cancer patients by doing the makeup for the patients. For example, they would wear wig, draw eyebrows, eyelines, put on lipsticks, and etc. This would help the patients not feel self- deprecating or ugly when they go out and integrate with the society. I would love to have this activity at Vietnam National Cancer Hospital." (In-depth interview - female patient, Department of Surgery E).

\section{Associated factors with the demands of the psychosocial support of cancer patients}

There are various associated factors for each specific demand. Based on the results of model 1, it is clear to see that after the adjustment of the following factors: genders, number of treatments, 
psychological states: shock and denial, anger, bargaining, there are two factors highly associated to their demands for visits of their health and their family's difficulties, which are the number of treatments and the psychological state of bargaining. As regards demands for this support of cancer patients with same gender, and three psychological states as stated, the first-timers have higher demands for visits of their health and their family's difficulties, specifically 2.2 times (1.19-4.14) higher compared to those who have received two or more treatment sessions. In addition, those with hope/ desire to overcome the illness have higher demands for visits (approximately 12 times with the confidence interval from 2.2 to 63.6), in comparison with those without belief in treatment process.

Table 2. Associated factors with the demands of the psychosocial support of cancer patients at Vietnam National Cancer Hospital using Multivariable Logistic Regression Analysis

\begin{tabular}{|c|c|c|c|c|}
\hline & \multirow[t]{2}{*}{ Model 1} & \multicolumn{3}{|c|}{$\begin{array}{l}\text { Having demands for visits about health } \\
\text { conditions and family's difficulties }\end{array}$} \\
\hline & & $N$ & $\%$ & OR $(95 \% C I)$ \\
\hline \multirow{2}{*}{ Gender } & Male & 167 & 82.3 & $0.64(0.33-1.23)$ \\
\hline & Female & 193 & 89.8 & 1 \\
\hline \multirow{2}{*}{$\begin{array}{l}\text { Number of } \\
\text { treatments* }\end{array}$} & First time & 217 & 90.0 & $2.22(1.19-4.14)$ \\
\hline & 2 times and more & 127 & 79.9 & 1 \\
\hline \multirow{2}{*}{$\begin{array}{l}\text { Psychological state: } \\
\text { Shock and Denial }\end{array}$} & Yes & 195 & 92.0 & $1.30(0.6-3.0)$ \\
\hline & No & 163 & 79.9 & 1 \\
\hline \multirow{2}{*}{$\begin{array}{l}\text { Psychological state: } \\
\text { Anger }\end{array}$} & Yes & 234 & 90.7 & $1.94(0.79-4.74)$ \\
\hline & No & 124 & 78.5 & 1 \\
\hline \multirow{2}{*}{$\begin{array}{l}\text { Psychological state: } \\
\text { Bargaining* }\end{array}$} & Yes & 354 & 86.8 & $11.83(2.2-63.57)$ \\
\hline & No & 3 & 42.9 & 1 \\
\hline & \multirow[t]{2}{*}{ Model 2} & \multicolumn{3}{|c|}{$\begin{array}{c}\text { Having demands for psychological } \\
\text { counselling, consultation }\end{array}$} \\
\hline & & $N$ & $\%$ & OR $(95 \%$ CI $)$ \\
\hline \multirow{2}{*}{ Gender* } & Male & 120 & 59.11 & $0.56(0.34-0.92)$ \\
\hline & Female & 166 & 77.21 & 1 \\
\hline \multirow{2}{*}{$\begin{array}{l}\text { Number of } \\
\text { treatments }\end{array}$} & First time & 176 & 73.03 & $1.47(0.90-2.38)$ \\
\hline & 2 times and more & 100 & 62.89 & 1 \\
\hline \multirow{2}{*}{$\begin{array}{l}\text { Psychological state: } \\
\text { Shock and Denial* }\end{array}$} & Yes & 178 & 83.96 & $2.49(1.35-4.60)$ \\
\hline & No & 107 & 52.45 & 1 \\
\hline \multirow{4}{*}{$\begin{array}{l}\text { Psychological state: } \\
\text { Anger* }\end{array}$} & Yes & 209 & 81.01 & $2.51(1.29-4.88)$ \\
\hline & No & 76 & 48.10 & 1 \\
\hline & Model 3 & \multicolumn{3}{|c|}{$\begin{array}{l}\text { Having demands for psychological } \\
\text { treatments }\end{array}$} \\
\hline & & $N$ & $\%$ & OR $(95 \% C I)$ \\
\hline \multirow{2}{*}{ Gender* } & Male & 84 & 41.87 & $0.72(0.47-1.11)$ \\
\hline & Female & 122 & 57.55 & 1 \\
\hline \multirow{2}{*}{$\begin{array}{l}\text { Number of } \\
\text { treatments }\end{array}$} & First time & 130 & 54.62 & $1.43(0.92-2.23)$ \\
\hline & 2 times and more & 68 & 42.77 & 1 \\
\hline \multirow{2}{*}{$\begin{array}{l}\text { Psychological states } \\
\text { Shock and Denial* }\end{array}$} & Yes & 138 & 66.03 & $2.21(1.28-3.82)$ \\
\hline & No & 68 & 33.33 & 1 \\
\hline
\end{tabular}




\begin{tabular}{|c|c|c|c|c|}
\hline \multirow{2}{*}{$\begin{array}{l}\text { Psychological states } \\
\text { Anger* }\end{array}$} & Yes & 158 & 61.96 & $2.10(1.19-3.70)$ \\
\hline & No & 48 & 30.38 & 1 \\
\hline \multicolumn{5}{|c|}{$\begin{array}{l}\text { Having demands for consultation on self- } \\
\text { care of appearance }\end{array}$} \\
\hline & & $N$ & $\%$ & OR $(95 \% C I)$ \\
\hline \multirow{2}{*}{ Gender* } & Male & 48 & 23.76 & $0.27(0.16-0.46)$ \\
\hline & Female & 111 & 54.15 & 1 \\
\hline \multirow{2}{*}{$\begin{array}{l}\text { Number of } \\
\text { treatments }\end{array}$} & First time & 99 & 42.49 & $1.20(0.70-2.07)$ \\
\hline & 2 times and more & 52 & 33.33 & 1 \\
\hline \multirow{2}{*}{$\begin{array}{l}\text { Psychological state: } \\
\text { Shock and Denial }\end{array}$} & Yes & 103 & 50.49 & $1.63(0.86-3.10)$ \\
\hline & No & 55 & 27.36 & 1 \\
\hline \multirow{2}{*}{$\begin{array}{l}\text { Psychological state: } \\
\text { Anger* }\end{array}$} & Yes & 118 & 47.20 & $2.38(1.15-4.95)$ \\
\hline & No & 40 & 25.81 & 1 \\
\hline \multirow{4}{*}{$\begin{array}{l}\text { Psychological state: } \\
\text { Acceptance }\end{array}$} & Yes & 114 & 36.19 & $0.63(0.35-1.11)$ \\
\hline & No & 44 & 48.89 & 1 \\
\hline & Model 5 & \multicolumn{3}{|c|}{$\begin{array}{c}\text { Having demands for social communication } \\
\text { consultation }\end{array}$} \\
\hline & & $N$ & $\%$ & OR $(95 \% C I)$ \\
\hline \multirow{2}{*}{ Gender* } & Male & 55 & 27.23 & $0.51(0.28-0.91)$ \\
\hline & Female & 102 & 49.76 & 1 \\
\hline \multirow{2}{*}{$\begin{array}{l}\text { Number of } \\
\text { treatments }\end{array}$} & First time & 105 & 45.06 & $1.63(0.97-2.75)$ \\
\hline & 2 times and more & 44 & 28.21 & 1 \\
\hline \multirow{2}{*}{$\begin{array}{l}\text { Psychological state: } \\
\text { Shock and Denial* }\end{array}$} & Yes & 108 & 52.94 & $4.43(2.26-8.69)$ \\
\hline & No & 48 & 23.88 & 1 \\
\hline \multirow{2}{*}{$\begin{array}{l}\text { Psychological state: } \\
\text { Anger }\end{array}$} & Yes & 113 & 45.20 & $0.75(0.37-1.52)$ \\
\hline & No & 43 & 27.74 & 1 \\
\hline \multirow{4}{*}{$\begin{array}{l}\text { Psychological state: } \\
\text { Acceptance }\end{array}$} & Yes & 112 & 35.56 & $0.62(0.35-1.09)$ \\
\hline & No & 44 & 48.89 & 1 \\
\hline & Model 6 & \multicolumn{3}{|c|}{$\begin{array}{c}\text { Having demands for Provision of } \\
\text { information support network for cancer } \\
\text { patients }\end{array}$} \\
\hline & & $N$ & $\%$ & OR $(95 \% C I)$ \\
\hline \multirow{2}{*}{ Gender* } & Male & 59 & 29.06 & $0.44(0.28-0.70)$ \\
\hline & Female & 42 & 19.72 & 1 \\
\hline \multirow{2}{*}{$\begin{array}{l}\text { Psychological state: } \\
\text { Shock and Denial* }\end{array}$} & Yes & 34 & 16.19 & $3.34(2.13-5.24)$ \\
\hline & No & 67 & 32.84 & 1 \\
\hline \multirow{2}{*}{$\begin{array}{l}\text { Psychological state: } \\
\text { Bargaining }\end{array}$} & Có & 97 & 23.83 & $1.48(0.24-9.01)$ \\
\hline & Không & 4 & 57.14 & 1 \\
\hline
\end{tabular}

*Statistical significant with $\mathrm{p}<\underline{0.05}$

In model 2, according to the factors after adjustment (gender, number of treatments and psychological states), two psychological states of shock and denial, and anger are two factors that highly associated and statistically significant to the cancer patients' demands for psychological counseling and 
consultation. Specifically, as regards patients with the same gender, the number of treatments, the patients with shock and denial psychological have higher demands for psychological consultation than others, which is 2.49 times $(1.35$ - 4.60). Similarly, after adjustment for other factors in the model, patients with anger psychological state have higher demands for psychological counseling and consultation, which is 2.51 times (1.29-4.88) higher than those do not have the same psychological state. In addition, men with the same characteristics also have demands for psychological counseling and consultation, but only 0.6 times $(0.34-0.92)$ as compared to women.

Similar to model 02's results, model 03 data also showed two psychological states: shock and denial, and anger being more associated with cancer patients in need of psychological therapy. The data indicated that for those with same gender, number of treatments, those with abnormal psychological states, such as shock and denial or anger, have higher demands for treatment at 2.21 times (1.12 - 3.82) and 2.1 times $(1.19-3.70)$ respectively, as compared to those who are mentally comfortable and stable.

As regards the 4th model, after the adjustment of remaining factors, psychological states and gender are factors associated to the patients' demands for consultation on self-care of appearance, specifically demands of those having psychological states of Anger are 2.38 times $(1.15-4.95)$ higher than those are not in same psychological state. Meanwhile, with the same number of treatments and psychological state, the male patients have lower demands for this type of support, at only 0.27 times $(0.16-0.46)$ as compared to female patients.

After adjusting for the remaining factors, the results of the 5th model showed that the psychological states of shock and denial, and gender are factors associated to the need for social communication consultation. With the same number of treatments, male patients' demands for this support account for only half $(0.28-0.91)$ as compared to female patients. Besides, patients having shock and denial states have demands for consultation which is 4.43 times $(2.26-8.69)$ higher than those do not have them similar psychological states.

In model 06, after adjustment, the two factors closely associated to cancer patients' demands for providing information of supporting network are the gender and psychological states of shock and denial. The data showed that, with the same psychological state, patients at the psychological state of denial, disbelief in the diagnostic results have higher demands for this support content, which is 3.34 times $(2.13$ - 5.24) higher than those who accept their diagnostic results. In particular, male patients wanting this support is only 0.44 times $(0.28-0.70)$ as compared to female patients.

\section{Discussion}

\section{Psychological states of cancer patients}

There are a number of studies in the world indicating that the rates of psychological disorders of cancer patients are different and are related to their pathological characteristics. A study of 150 cancer patients in Iran for two years from 2012 to 2013 showed that the spectrum of depression (symptomatic plus mild depression) was $48 \%$ and anxiety spectrum (symptomatic plus mild anxiety) was $46 \%$. Patients with breast and stomach cancer have the highest rate of anxiety and depression as compared to that of all other cancer patients (Nikbakhsh N, Moudi S, Abbasian S, Khafri S, 2014). Rates of cancer patients having mental disorders ranged from $5 \%$ to $50 \%$, from 0 to $46 \%$ for depressive disorder and from $1 \%$ to $49 \%$ for anxiety disorders (Derogatis LR, Morrow GR, Fetting J, et al, 1983). In comparison with the study outcomes, the percentage of cancer patients having depressive disorders in our study ranged from 0 to $46 \%$, but that of cancer patients having anxiety, stress, and excitability is higher, accounting from $1 \%$ to $49 \%$ (Harter M, Reuter K, Aschenbrenner A, et al., 1990). Unlike existing studies, our study has shown the percentage of cancer patients who believe in the desired treatment and hope to be cured, and the number of patients with the psychological state of "Acceptance" is higher than those who show the signs of shock and denial, anger, and depression. This can be explained that the study used the Kubler-Ross's model (1969) of severe patients rather than use only the usual depressive or anxiety scales regularly used for patients such as Hospital Anxiety and Depression Scale (HADS), 
Depression, Anxiety and Stress Scales (DASS 21), or State-Trait Anxiety Inventory (STAI), etc. In addition, most of the cancer patients participating in the study come for treatment for the first time, so they have several psychological symptoms such as shock, stress, anxiety and excitability. Nevertheless, during the course of treatment at Vietnam National Cancer Hospital, the patients gradually acquire the psychological state of accepting the disease, believing in the treatment process and hoping it to conduct successfully, as well as accept their health conditions, are ready to live with the disease and accept the worst-case scenario that can happen.

\section{Demands for psychosocial support of cancer patients}

In this study, there is a variation of cancer patients' demands for contents of psychosocial support, with the highest rate of demands for visits about patients' health and family situations, followed by demands for receiving information about the supporting network and psychological counselling - consultation. Other demands having lower rates include psychotherapy, consultation on the self-care of appearance and social communication.

Cancer patients need to be visited about their health and family circumstances, provided information about the cancer patient supporting network, as well as psychological counseling - consultation. Our study results have similarities with the work of Vu Thi Thu Phuong and Ly Thi Hao (2016) on social work for blood cancer patients at the National Institute of Hematology and Blood Transfusion (NIHBT) with the rate of oscillation from 70-90\% (Ly Thi Hao, 2016). This can be explained as most of the patient comes to the hospital for the first time, more than half of them have a psychological state of shock, disbelief in the diagnosis, and inevitably confused, furthermore they are restricted to access to information about supporting network. In addition, cancer is a specific disease, unlike normal conditions which requires relatively long and high-cost treatment. As a result, the patients desire for care and visits about their family's difficulties, along with the provision of psychological counselling and consultation. In fact, at Vietnam National Cancer Hospital, the medical staff and social workers regularly visit and talk about the patients' health conditions and difficulties, and they hope that the hospital will continue to maintain and promote these supporting activities.

Experience of countries around the world showed that one of the most underlined services that need providing to cancer patients is psychotherapy, while those demands of cancer patients who are psychologically treated and partook in this study accounts for a modest proportion. In reality, at Vietnam National Cancer Hospital, the perception of patients and families in psychotherapy remains very limited. Psychotherapy has not been implemented at Vietnam National Cancer Hospital and this is a very new term for patients and their families. They do not fully understand psychotherapy's role and significance in the course of treatment.

The study results are similar to a research by Nguyen Ha My in 2016. The demands of cancer patients for consulting on how to care for themselves and on social communication varied from $35 \%$ to $45 \%$. This is in fact demands of female cancer patients (Nguyen Ha My, 2016).

\section{Associated factors with demands of psychosocial support of cancer patients}

In general, the study showed that factors directly associated to cancer patients' demands for psychosocial support include gender, number of treatments, psychological states (especially states of shock and denial, and anger). The percentage of female patients with demand for psychosocial support is higher than men. This can be explained the negatively psychological states of female patients are higher than male patients as the study's findings.

As compared to the other five contents of psychosocial support, demands for visits of health and family's difficult circumstances of first-time patients are higher than those of patients receiving treatment twice or more. The statistics showed that the majority of cancer patients having demands for this support are in working age and maybe the family's breadwinners. In addition, the treatment cost is relatively large. This leads to the patients and their families being affected and meeting several 
difficulties in life and society. Therefore, first-time patients not only want to be concerned about their health but also want to be paid attention to their family circumstances.

As regards the demands of psychological support, the research is particular interest to patients with mental health problems, particularly those with the psychological states of shock, disbelief in the diagnosis results (Shock and denial); stress, anxiety, excitability (Anger); silence, crying, grief (Depression). The patients with mental health problems evidently need support with psychological counselling and consultation, psychological therapy, consultation on how to care for their own appearance; social communication consultation and provision of information support network for cancer patients (especially those at the psychological states of shock and denial). However, this does not mean that patients with other psychological states of believing in treatment; hoping to overcome the illness (Bargaining); Acceptance to face the worst situation and living with the disease (Acceptance), do not have demands for psychological support. The research data indicated that the patients at the psychological state of bargaining still need visits of their health conditions and family's difficulties. This can be explained that the psychology of cancer patients is one of the main factors affecting the effectiveness of treatment. They need attention and support from the medical staff and social workers to help strengthen their beliefs and hopes for winning the disease. Meanwhile, these kind of psychosocial support activities for cancer patients remain very insufficient. The hospital only focuses on the treatment for their patients.

\section{Conclusion}

The study gave an overview of the demands for psychosocial support of cancer patients at Vietnam National Cancer Hospital. The results showed that, the cancer patients' demands for six contents of psychosocial support were at various rates. Furthermore, the study clearly indicated an association between the patients' demands for psychosocial support with gender, the number of treatments, and psychological states. These are evidence with scientific significance for the Vietnam National Cancer Hospital's care and attention when having to meet the psychosocial needs of cancer patients effectively.

\section{References}

World Health Organization (WHO) (2017). World's health ministers renew commitment to cancer prevention and control. 2017; http://www.who.int/cancer/media/news/cancer-preventionresolution/en/

Ministry of Health (2015). Communication on cancer prevention.

Nikbakhsh N, Moudi S, Abbasian S, Khafri S. (2014). Prevalence of depression and anxiety among cancer patients. Caspian Journal of Internal Medicine, 5(3):167-170.

Derogatis LR, Morrow GR, Fetting J, et al. (1983). The prevalence of psychiatric disorders among cancer patients. JAMA, 249(6):751-757.

van't Spijker A, Trijsburg RW, Duivenvoorden HJ (1997). Psychological sequelae of cancer diagnosis: a meta-analytical review of 58 studies after 1980. Psychosom Med, 59(3):280-293.

Sellick SM, Crooks DL (1999). Depression and cancer: an appraisal of the literature for prevalence, detection, and practice guideline development for psychological interventions. Psychooncology, 8(4):315-333.

Harter M, Reuter K, Aschenbrenner A, et al (2001). Psychiatric disorders and associated factors in cancer: results of an interview study with patients in inpatient, rehabilitation and outpatient treatment. European journal of cancer (Oxford, England : 1990), 37(11):1385-1393.

Zabora J, BrintzenhofeSzoc K, Curbow B, Hooker C, Piantadosi S. (2001). The prevalence of psychological distress by cancer site. Psychooncology, 10(1):19-28.

Vu Thi Thu Phuong (2016). Social work in hospital from the reality of Hemophilia Center. Graduate Academy of Social Science, Hanoi, Vietnam, : National Institute of Hematology and Blood Transfusion (NIHBT). 
Ly Thi Hao (2016). Social work for patients with blood diseases from the reality at National Institute of Hematology and Blood Transfusion (NIHBT). Graduate Academy of Social Science, Hanoi, Vietnam, : National Institute of Hematology and Blood Transfusion (NIHBT).

Nguyen Ha My (2016). Social work with individual in psychosocial support for patients after the diagnosis of breast cancer: Thanglong University, Hanoi, Vietnam,. 